\title{
Les populations autochtones de maïs au Mexique
}

Importance, conservation in situ et amélioration génétique

Native corn populations of Mexico: importance, conservation, and breeding

Poblaciones nativas de maíz de México: importancia, conservación y

mejoramiento

\section{Rafael Ortega Paczka}

\section{(2) OpenEdition}

\section{Journals}

Édition électronique

URL : https://journals.openedition.org/ethnoecologie/7183

DOI : 10.4000/ethnoecologie.7183

ISSN : 2267-2419

Éditeur

Laboratoire Éco-anthropologie

Référence électronique

Rafael Ortega Paczka, «Les populations autochtones de maïs au Mexique », Revue d'ethnoécologie [En ligne], Supplément 2 | 2021, mis en ligne le 25 novembre 2021, consulté le 20 décembre 2021. URL http://journals.openedition.org/ethnoecologie/7183; DOI : https://doi.org/10.4000/ethnoecologie. 7183

Ce document a été généré automatiquement le 20 décembre 2021.

\section{cc) (†) $\odot$}

Revue d'ethnoécologie est mis à disposition selon les termes de la licence Creative Commons Attribution - Pas d'Utilisation Commerciale - Pas de Modification 4.0 International. 


\title{
Les populations autochtones de maïs au Mexique
}

\author{
Importance, conservation in situ et amélioration génétique \\ Native corn populations of Mexico: importance, conservation, and breeding \\ Poblaciones nativas de maíz de México: importancia, conservación y \\ mejoramiento
}

Rafael Ortega Paczka

\section{Introduction}

1 L'objectif de cet article est d'examiner l'importance de la conservation in situ et l'amélioration participative des maïs autochtones du Mexique en soutenant ces activités par des projets de collaboration entre des communautés rurales et professionnelles.

Dans la première partie, nous notons les particularités de la culture et en général les savoirs traditionnels qui se développent autour de la culture du maïs au Mexique, ce qui explique la nécessité de la préservation in situ et la sélection participative de l'espèce dans le pays. Le Mexique est le lieu d'origine, de domestication et de diversification de la plante ; celle-ci est la base de l'alimentation de ce pays où son grain se consomme dans une grande diversité de plats, mais l'usage de la plante entière est aussi très important pour le fourrage et autres activités. Fréquemment, un usage alimentaire correspond à la culture d'une variété de maïs. Au Mexique il est la principale culture; elle occupe approximativement $40 \%$ de la surface récoltée annuellement (ce sont 7200000 hectares de maïs seul ou associé pendant les 40 dernières années selon l'INEGI 2015). En effet, le maïs est fréquemment semé en association avec d'autres plantes dans le système de la milpa, notamment dans les aires rurales où la plante est très respectée et surtout dans certaines régions agricoles où elle est au centre de rituels de cérémonies. 
3 Malgré les programmes de sélection génétique et de production de semences hybrides mis en place par le gouvernement depuis au moins 70 ans, les hybrides et les variétés sélectionnées sont semées sur environ $22 \%$ de la surface, le restant étant occupé principalement par des semences obtenues des cultures indigènes issues des variétés cultivées par les petits agriculteurs (cinq hectares ou moins), mais aussi de la culture de générations améliorées d'hybrides commerciaux (Aquino et al. 2001).

4 Les maïs sélectionnés et améliorés sont cultivés dans les meilleurs sols irrigués et jouissent de climats tempérés. Au contraire, les maïs natifs sont cultivés dans des conditions climatiques et avec des méthodes agricoles très variées, et l'on observe que chaque population native évolue dans une marge très réduite de conditions. Ainsi une grande diversité de populations a été créée, environ 60 variétés, ce qui représente au niveau mondial la plus grande diversité nationale.

5 Dans la seconde partie, nous évoquons en termes très généraux, les recherches qui ont été menées sur la diversité du maïs ainsi que les principales tendances et problématiques liées à l'amélioration génétique de la plante, dans ce pays.

6 Dans la troisième partie, nous approfondissons les expériences d'amélioration participative du maïs au Mexique. Il existe de nombreuses modalités de cette amélioration; elles résultent de l'ensemble des réponses aux interrogations qui surgissent du matériel d'origine pris pour l'amélioration, la méthode de sélection et le but à poursuivre. Ensuite, les sujets suivants sont approfondis :

- la méthode de Sélection Massale Visuelle Stratifiée (SMVE);

- la méthode qui, à partir des variétés de maïs agencées avec les maïs eux-mêmes améliorés par des variétés déjà sélectionnées, combine ainsi les avantages des progéniteurs et élimine leurs faiblesses. Plus loin, nous énonçons les modes de participation des agriculteurs et des sélectionneurs dans la sélection participative. Finalement, nous exposons les principales difficultés à ce type de projet au Mexique.

7 Les raisons antérieures ajoutées à la menace de l'autorisation de la culture des maïs transgéniques sont la cause de ce qu'entre 1995 et 2013 diverses institutions gouvernementales et non-gouvernementales ont instauré d'importants projets centrés sur les maïs indigènes. Ces projets incluent des travaux de récolte, des études et des travaux de conservation in situ, d'évaluation et d'amélioration génétique. À ce sujet, les sélectionneurs et les agriculteurs ont développé divers modes de sélection participative.

8 Soulignons que cet article traite exclusivement de la conservation in situ, de la sélection des semences et du fait qu'il est indispensable d'accompagner ces pratiques avec, au moins, l'amélioration des terres et des méthodes de conservation de l'humidité des sols. Ainsi, grâce à l'amélioration de la gestion des cultures et la promotion de marchés pour cette diversité variétale de maïs, on obtiendrait de multiples effets bénéfiques. 


\title{
Particularités de la culture de la plante et impact culturel autour du maïs au Mexique
}

\author{
Mexique : centre d'origine, de domestication et de diversité du maïs \\ ainsi que de ses usages
}

Le centre d'origine, de domestication et de diversité primaire du maïs se situe au Mexique, au nord de l'Amérique centrale. (Vavilov 1994, Matsuoka et al. 2002, Kato 2009). Les centres de diversité biologique des plantes cultivées sont aussi des centres de diversité des usages (Ortega 2003a). Le Mexique cultive et utilise le maïs depuis 7000 ans et de nombreux usages des différentes parties de la plante y ont été développés (Beas 1982), mais l'on constate fréquemment que chaque usage requiert une ou plusieurs variétés de maïs spécifiques (Ortega 2003a).

10 La surface annuelle de la culture du maïs oscille, depuis 35 ans, en moyenne autour de 7200000 ha (résultats donnés par INEGI 2015) sur une superficie totale de 18000000 ha cultivés (Lépiz \& Rodríguez 2006). Nous évaluons que, de cette surface totale de maïs, au moins 5000000 ha sont cultivés en variétés locales tandis que près de 1584000 ha (22\%) sont cultivés en hybrides de première génération et 616000 ha avec des générations avancées de maïs sélectionnés, appelés aussi « hybrides créolisés».

11 Comme résultat, le Proyecto Global de Maices Mexicanos (Projet global des maïs mexicains) organisé par la CONABIO (Comisión nacional para el conocimiento y uso de la biodiversidad, Commission nationale pour la connaissance et l'utilisation de la biodivertsité) de 2006 à 2012, établit qu'il y a 64 'races' de maïs au Mexique qui sont amplement reconnues par les experts (CONABIO 2011). Ainsi, le Mexique prend la première place avec une telle diversité.

\section{Au Mexique, le grain de maïs s'utilise principalement pour l'alimentation, mais les autres parties de la plante sont utilisées de diverses façons}

12 Le maïs est principalement cultivé pour son grain ; s'il est principalement utilisé pour la consommation humaine, il est également important pour l'alimentation animale (bovins, porcins, volailles et équidés, etc.) Par ailleurs, le grain est aussi utilisé dans l'industrie et même pour l'artisanat et les cérémonies rituelles (Beas 1982).

13 Les jeunes épis de maïs (elote) cuits à la vapeur ou grillés de diverses façons sont également très importants pour la consommation humaine. Quand les grains des jeunes épis sont attaqués par le champignon " cuitlacoche » (Ustilago maydis), on les consomme dans de délicieux plats (Figure 1). Dans la plupart des zones agricoles, on fait profit de toutes les parties de la plante verte ou sèche, pour un ou divers usages (Beas 1982). Les plantes vertes stériles (sans épis), les rejetons improductifs et les épis une fois la pollinisation terminée servent aussi à nourrir le bétail. 
Figure 1 : Lorsque les grains des jeunes épis de maïs sont infectés par le champignon cuitlacoche (Ustilago maydis), ils sont utilisés pour la préparation de délicieux plats

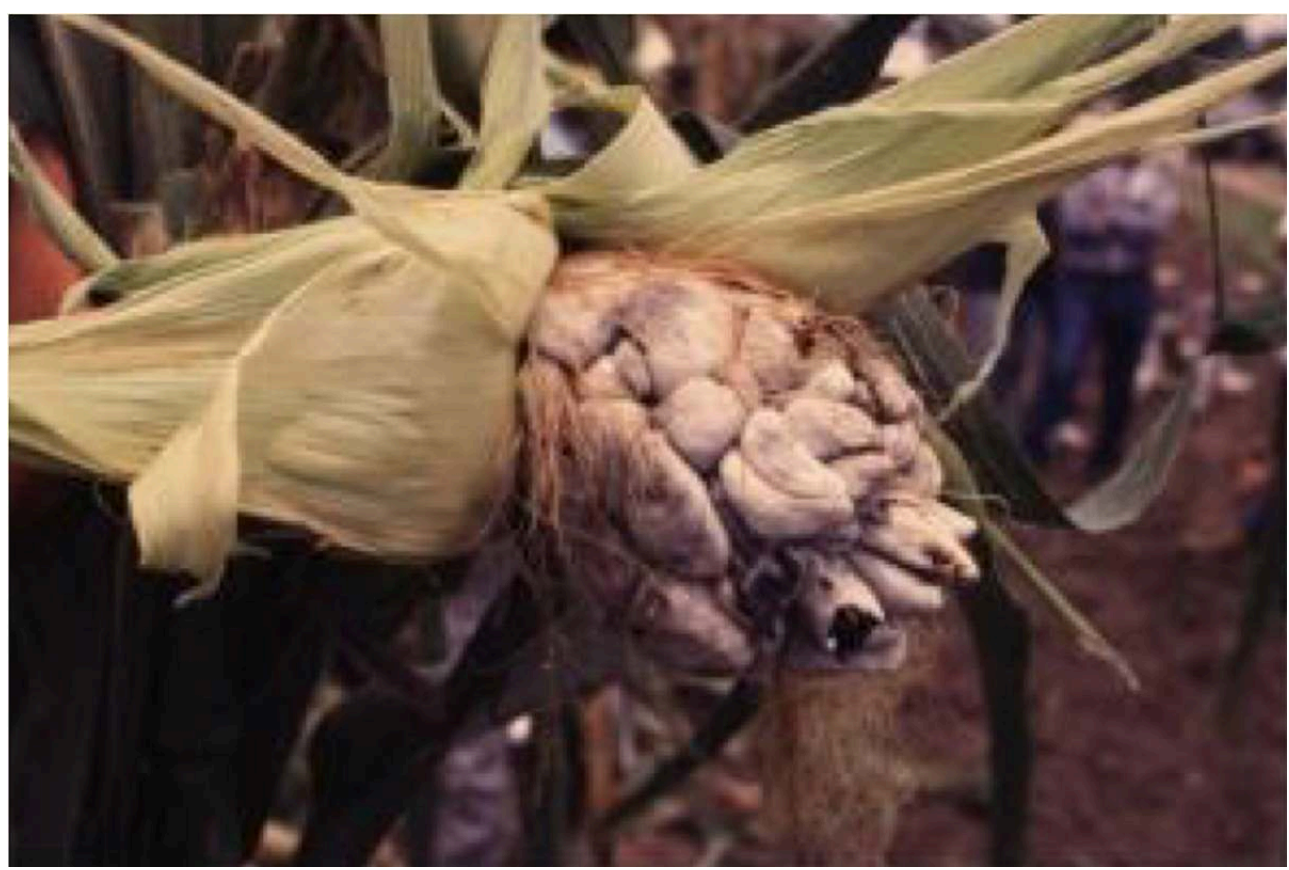

(c) R. Ortega Paczka

Les feuilles qui enveloppent l'épi servent à envelopper les tamales (crêpes de maïs fourrées de divers aliments), comme fourrage, pour l'artisanat et autres usages. Dans plusieurs régions du Mexique, le séchage et la vente des feuilles de l'épi sont une source économique importante. (Figure 2). Les feuilles qui entourent le maïs (olotes), la base de la tige et la racine peuvent aussi s'utiliser comme carburant. Les tiges sèches servent souvent de clôture. Avec les bractées qui entourent l'épi, les graines et autres parties de la plante, on réalise divers objets d'artisanat. (Figure 3).

Figure 2 : Dans plusieurs régions du Mexique, l'extraction et la vente des feuilles (bractées) qui entourent l'épi de maïs, constituent une activité économique locale lorsque la récolte est à la maison

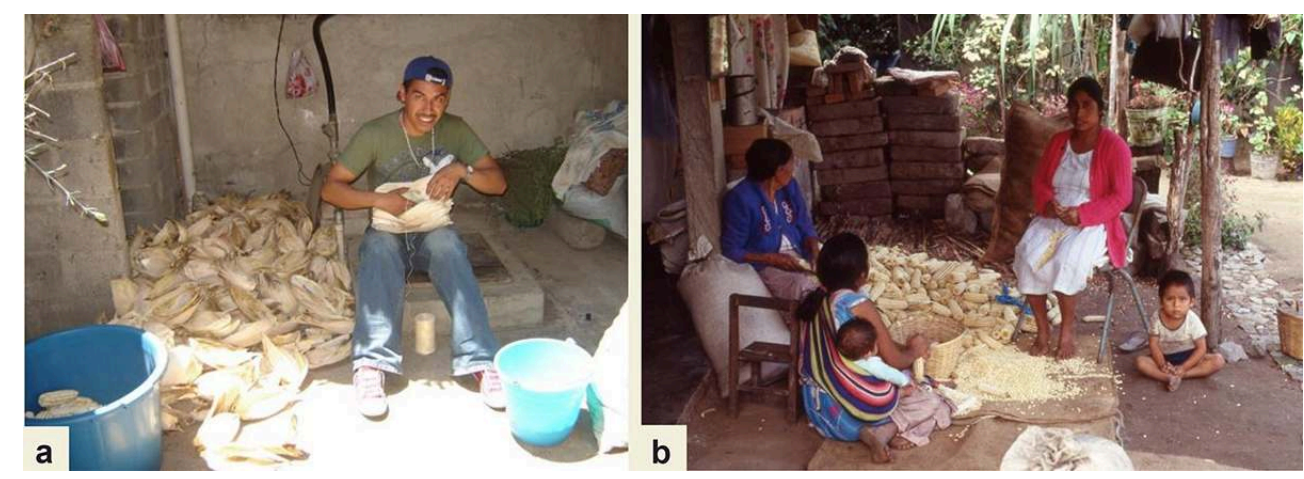

(c) R. Ortega Paczka 
Figure 3 : Artisanat réalisé avec des bractées qui enveloppent l'épi (a) et avec des grains de maïs et d'autres plantes (b et c)

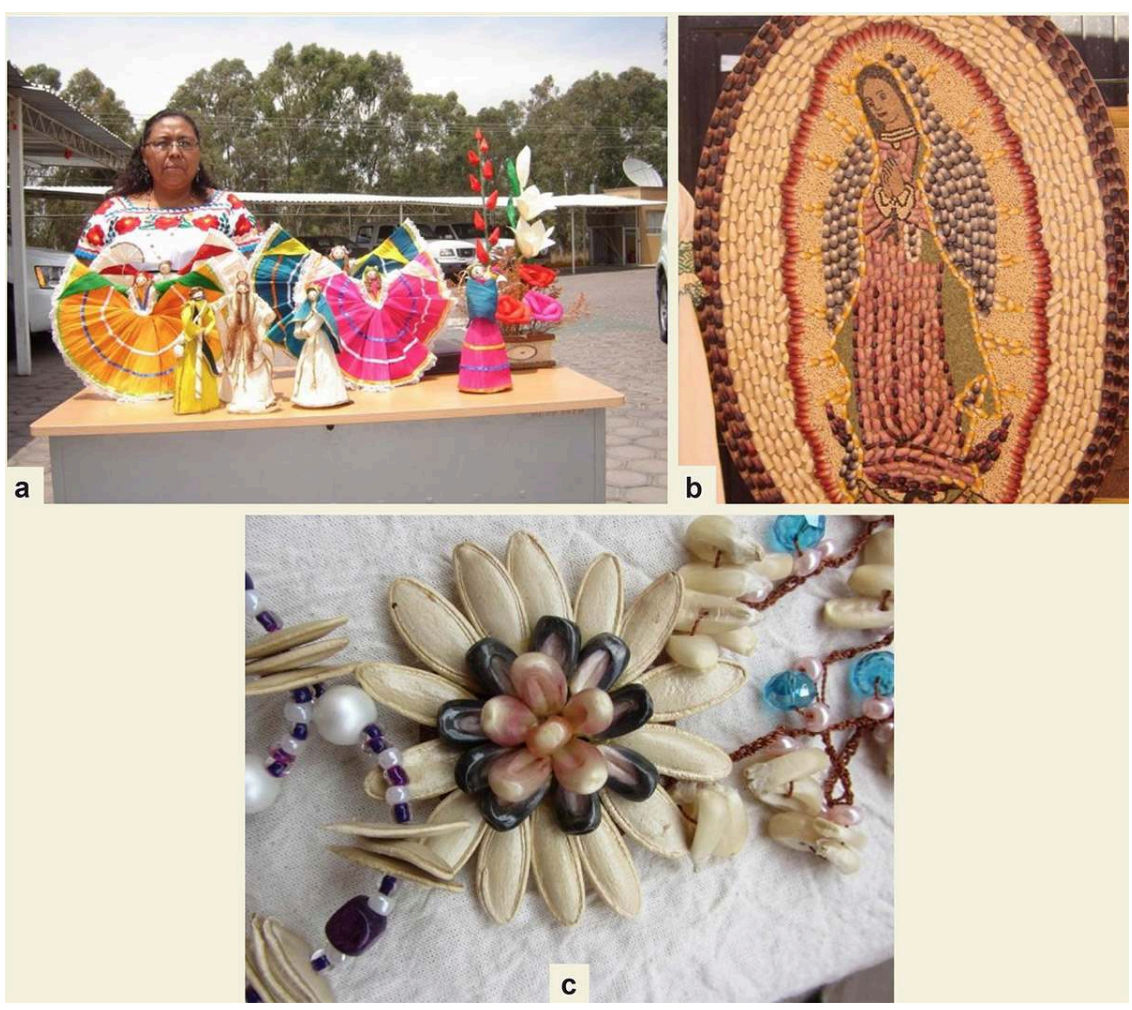

(c) R. Ortega Paczka

\section{La diversité des conditions et des objectifs de la culture du maïs conduit à une forte diversité génétique de la plante}

Durant les 40 dernières années, la surface du maïs cultivé au Mexique a été en moyenne de 7200000 ha, ce qui représente la moitié de la surface totale cultivée ; cette culture s'étale du niveau de la mer jusqu'à 3400 mètres d'altitude et de la frontière nord du pays jusqu'à la frontière sud, dans des climats chauds, humides et sous-humides (Af, Am y Aw), chauds secs et mégathermiques (BS h), chauds secs et micro-thermiques (BS $\mathrm{k})$ et tempérés sous-humides ( $\mathrm{Cm}$ et $\mathrm{CW}$ ). En période de pluie, on le cultive dans les lieux où les précipitations vont de $300 \mathrm{~mm}$ jusqu'au-delà de $3000 \mathrm{~mm}$. Selon les zones climatiques, on le cultive avec plus ou moins d'irrigation, mais au cœur des régions désertiques, l'irrigation est indispensable. Dans la plupart des zones, on ne le cultive qu'en période de pluie et dans les régions tropicales, on obtient fréquemment deux récoltes par an (Ortega 1977).

Le maïs se cultivant dans des milieux très différents et ayant une grande variété d'usages, les maïs natifs occupent généralement une superficie très restreinte et un usage du grain particulier. L'adaptation à une telle diversité de conditions environnementales et à un si grand nombre d'usages a multiplié les variétés, types et races de maïs, que les paysans mexicains ont formés et conservés pendant des millénaires de sorte qu'ils sont devenus fondamentaux pour eux (Wellhausen et al. 1951, Ortega 2003a) (Figures 4 et 5). 
Figure 4 : Diversité du maïs dans certaines régions du Mexique. Exemples du maïs de l'État de Guerrero (a), de la Sierra de Chihuahua (b) du sud-est de l'État de Mexico (c) et la Sierra Norte de Puebla (d)

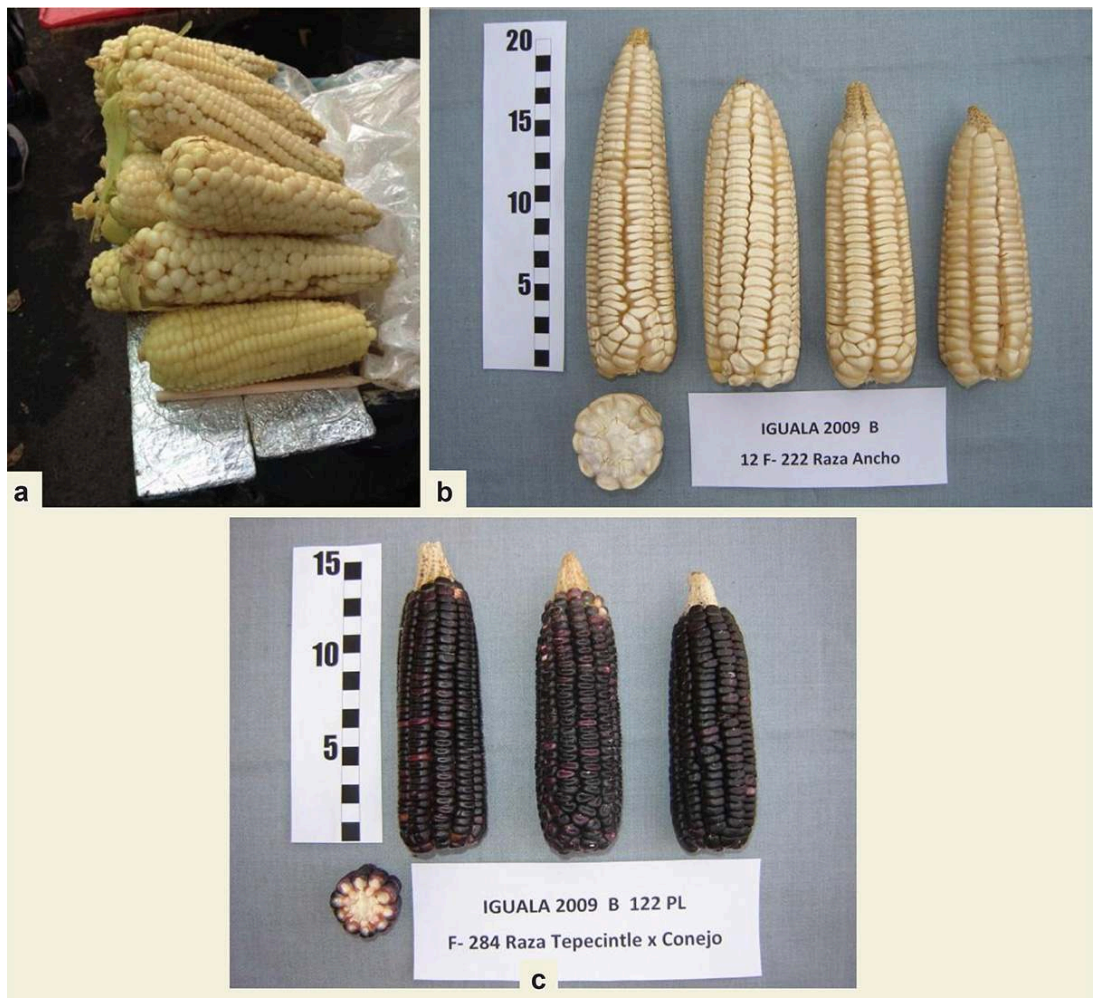

(c) R. Ortega Paczka 
Figure 5 : Un maïs natif a une zone d'adaptation très restreinte et une utilisation particulière du grain, par exemple, le maïs Cacahuacintles des hautes terres est consommé comme jeune maïs et pozole (a), le maïs large, de hauteurs intermédiaires, est utilisé spécialement pour le pozole (b) et le maïs coloré pour les collations (c).
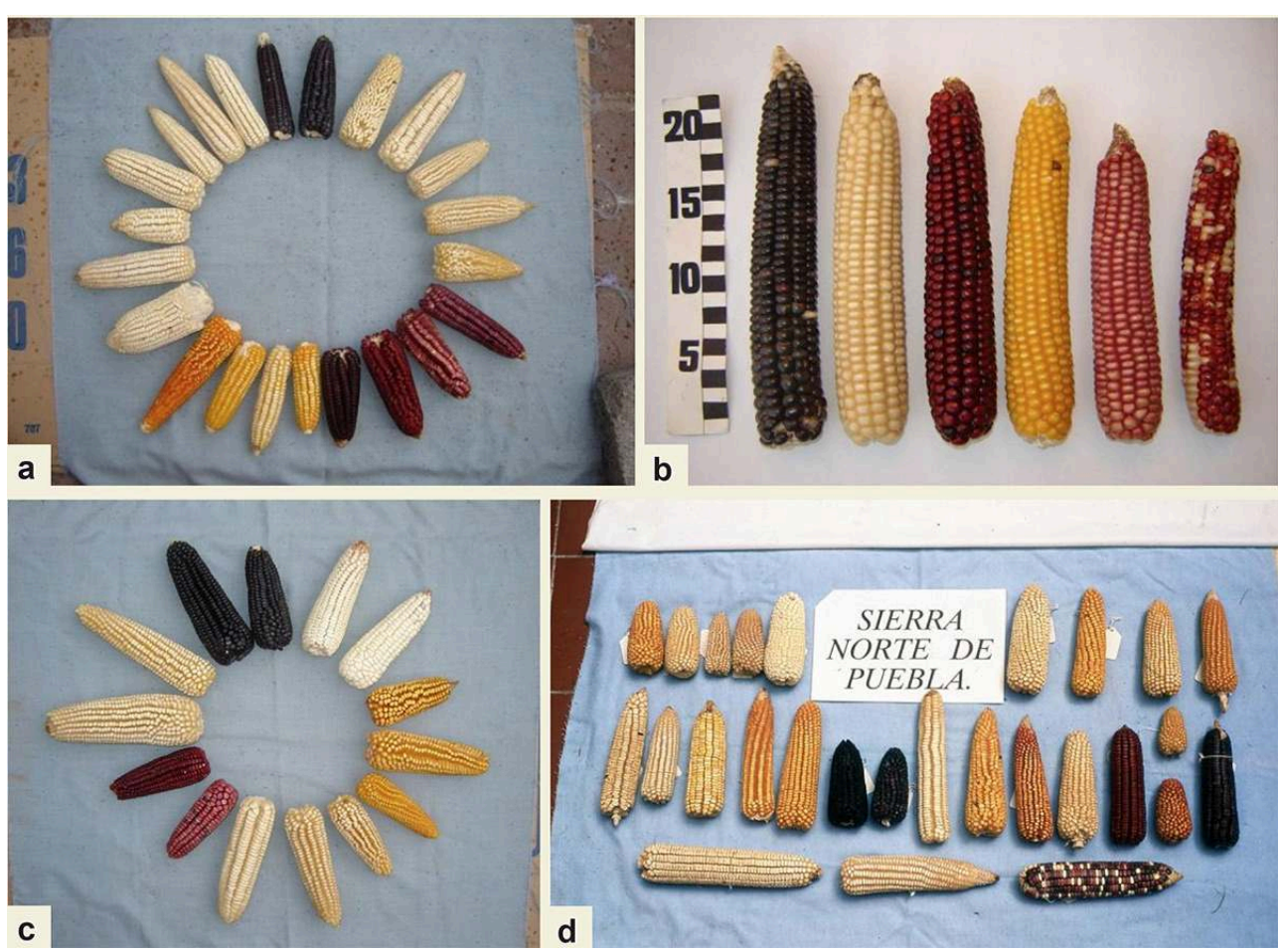

(c) R. Ortega Paczka

Ce sont près de deux millions de familles paysannes, $80 \%$ de celles qui cultivent le maïs, qui sélectionnent leur semence à partir de leur culture et qui ne cultivent que des variétés locales. Ce travail fondamental de conservation et d'évolution du maïs au Mexique a été peu valorisé. Fréquemment, un agriculteur sème une partie de son terrain avec une sorte de maïs et le reste avec une autre, ou bien un agriculteur sème une variété et les voisins une autre et même si ces cultures sont très proches les unes des autres, les variétés locales se maintiennent plus ou moins pures à partir de la stricte sélection des semences réalisée par les familles paysannes. C'est pourquoi le maïs aujourd'hui comprend plusieurs millions de populations.

Le maïs est souvent cultivé avec des haricots, des courges et d'autres plantes; ce système profite à de nombreuses herbacées et arbres fruitiers existant dans les parcelles; cet écosystème est nommé milpa et il en existe plusieurs modalités dans le pays. Le système de la «milpa» est très variable, actuellement il inclut des plantes natives mais aussi des plantes introduites comme la fève (Vicia fava L.) ou le xpelón (le haricot à œil, Vigna unguiculata L.), cette-dernière s'associe souvent avec le maguey (Agave sp.) ou des arbres fruitiers provenant de divers lieux du monde (Figure 6). Dans les zones tropicales où les sols sont peu profonds, la culture de la milpa se prolonge sur une ou plusieurs années consécutives et alterne avec des périodes de repos des terrains, pendant lesquelles la végétation naturelle se rétablit (Figure 7). 
Figure 6 : Quelques variantes de l'agroécosystème milpa mexicain

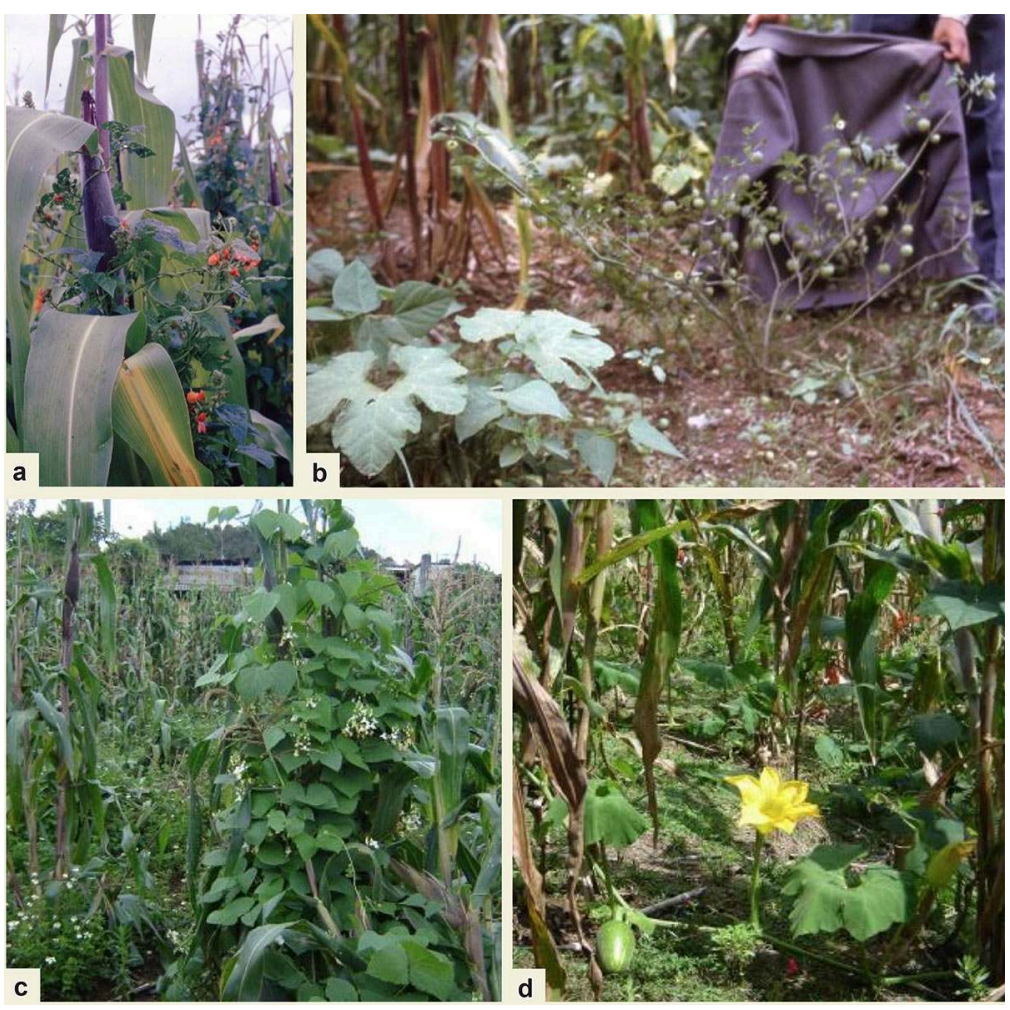

(a) Association de maïs et de haricots près de la ville de Mexico ; (b) Champ de maïs dans la Sierra Norte de Puebla qui comprend du maïs, des tomates en coque et du chilacayote ; (c) Maïs avec haricots communs à Los Altos de Chiapas ; (d) Maïs avec courge près de Mexico.

(c) R. Ortega Paczka

Figure 7 : Paysage montrant trois phases de la milpa à Nilchí, Campeche : forêts, terres prêtes à être plantées et restes de milpa déjà récoltés

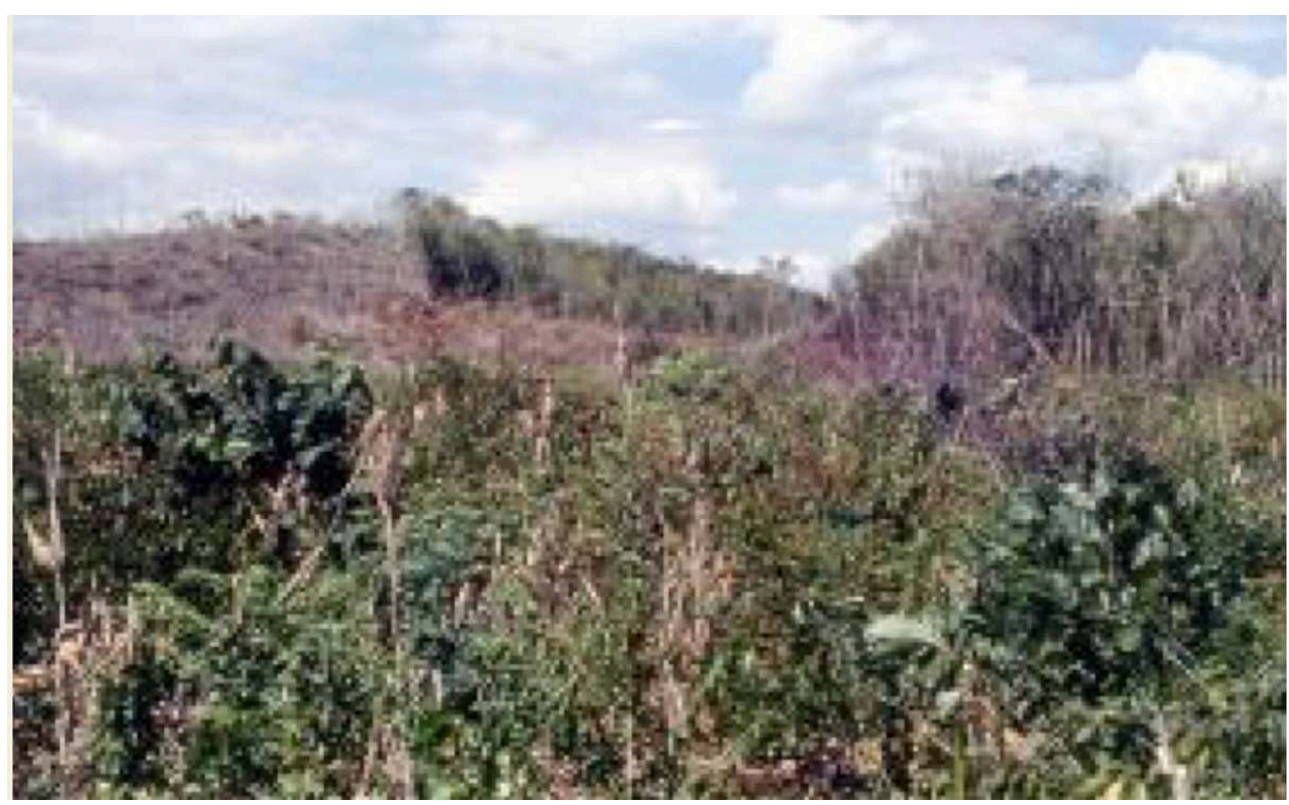

(c) R. Ortega Paczka 
19 Pour comprendre et localiser l'immense diversité de populations natives des maïs, les académiciens et les populations en général classent les maïs en races, bien que la plupart des populations natives de maïs comprennent deux ou plusieurs races. Ce concept de race a été introduit par Anderson et Cutler (1942), il a été exploité pour comprendre la diversité des maïs au Mexique par Welhausen et al. (1951) et beaucoup d'auteurs postérieurs. Sanchez et al. (2000) et CONABIO (2011) ont actualisé les races du maiis au Mexique qui sont les plus répandues parmi les spécialistes.

\section{Études des cultivars natifs et sélection génétique des maïs au Mexique}

La sélection moderne au Mexique depuis les années 70-75 n'utilise que 5 des 59 races et s'est dédiée à obtenir des hybrides et des variétés locales de grain de couleur blanche ou crème pour, essentiellement, la confection des tortillas standard des populations urbaines; ceci dit, ni les variétés améliorées ni les hybrides n'ont été conçus pour l'immense diversité régionale des tortillas traditionnelles. La sélection s'est uniquement faite pour quatre sortes de climats et de sols: 1) tropicaux, 2) chauds et secs avec irrigation, 3) Les terres basses et les plaines du Jalisco et 4) Les hauts plateaux du centre (Ortega 1977). En somme, les travaux de sélection n'ont toujours pas été propagés sur de vastes territoires et n'ont pas incorporé la grande diversité de types de maïs existant au Mexique.

21 Depuis l'entrée en scène des nord-américains en 1944, les programmes de sélection et de production des semences ont privilégié les hybrides par rapport à d'autres sortes de maïs améliorés à pollinisation ouverte; en effet, ces derniers ne nécessitent pas l'achat des semences tous les ans, car la semence vient de la récolte de l'agriculteur sans baisse de rendement. Ce qui met en lumière la faiblesse des politiques publiques, car il est évident que certaines variétés à pollinisation libre, comme celles diffusées par la Fondation Rockefeller et le CAFIME créé par l'Antiguo Instituto, sont toujours en possession des agriculteurs qui les sèment depuis plusieurs générations sans que les programmes gouvernementaux incitent à leur adoption.

De 1944 à 1955, les techniciens de l'oficina de Estudios Especiales (Office d'études spéciales), institution parrainée et soutenue par la Fondation Rockefeller et le gouvernement mexicain, ont mené des travaux intensifs de récolte et d'étude des populations indigènes de maïs qui ont donné lieu à plusieurs ouvrages dont «Razas de maíz en México " (Les races de maïs au Mexique) (Wellhausen et al. 1951). Puis vint une période où les travaux se sont focalisés sur l'amélioration génétique pour obtenir des hybrides issus d'une quantité réduite de populations indigènes de maïs, et reconnues comme des plantes de rendement et de caractéristiques supérieurs. Parallèlement, pendant un certain temps, les milieux académiques et gouvernementaux ont considéré la sélection paysanne des semences comme appartenant au passé et ont prôné que l'amélioration du maïs devait être prise en main par les obtenteurs et leurs collaborateurs (Ortega \& Ángeles 1978).

Malgré les efforts considérables fournis par les sélectionneurs, les producteurs de semences, les vulgarisateurs, les organismes de crédit et les entreprises d'agrochimie et de semences pour promouvoir la culture du maïs amélioré, notamment des hybrides, la semence brevetée n'a jamais été semée au-delà de $33 \%$ de la surface occupée par le 
maïs au Mexique; et on a récemment calculé que cette surface s'est réduite à $22 \%$ (Aquino et al. 2001) á cause de la diminution des aides et des subventions aux ruraux. Cela est dû en partie : a) à l'inexistence des variétés de maïs améliorées dans plusieurs régions, b) au coût élevé des semences, c) aux fréquents problèmes posés par la mauvaise qualité de la semence, d) à ce que les rendements dans les champs des agriculteurs égalent fréquemment et souvent dépassent les maïs hybrides, car ceux-ci ont été testés et sélectionnés dans des sols profonds et souvent irrigués. En revanche, dès le début de la sélection génétique, la culture d'« hybrides créolisés " a été très importante; ce sont des générations améliorées de maïs sélectionnés dont la semence est obtenue par les paysans à partir de leurs propres récoltes. À ce propos, il est important de souligner, que même si la propagation de celles-ci n'a pas été établie, nous estimons que, dans différentes périodes, elles ont couvert autour de $20 \%$ de la superficie du maïs cultivée dans le pays (Ortega 2003a), et aujourd'hui environ $8,5 \%$.

Il reste donc 50 à $60 \%$ de la surface occupée par les populations natives de maïs plus ou moins pures et $20 \%$ d'hybrides créolisés dont les producteurs se servent pour sélectionner les semences, les conserver et améliorer les caractéristiques de leur culture. Ces pourcentages incluent tous les maïs qui ne sont pas utilisés à la confection des tortillas traditionnelles, c'est-à-dire les maïs de spécialité.

En raison du déficit de la production nationale de maïs au milieu des années 1960 l'Instituto Nacional de Investigaciones Agrícolas (Institut National de recherches agricoles) a établi des programmes de sélection dans des aires climatiques non-desservies antérieurement; les premiers travaux consistaient à récolter, évaluer et établir des programmes de sélection des populations natives de maïs qui présentaient des résultats exceptionnels en rendement et en caractéristiques agronomiques. Pendant cette période, le professeur Efraim Hernàndez Xolocotzi a publié la récolte et l'étude des populations natives de maïs dans les lieux du pays où elles n'avaient pas été recueillies jusqu'à ce moment-là ; ces programmes ont mis en évidence l'intérêt pour l'agriculture paysanne, pour les populations indigènes de maiis et pour la sélection paysanne des semences (Ortega \& Angeles 1978). Cependant, au milieu des années 1980, ces travaux de collecte, étude et exploitation des programmes d'amélioration des populations indigènes ont été quasiment abandonnés en raison de la crise économique qui a dévasté le Mexique à partir de l'année 1983, ainsi que l'imposition, dans les programmes de sélection des maïs du pays, de l'usage des «pool génétiques » du maïs du CIMMYT qui inclut le matériel génétique d'autres pays.

Dès l'entrée du maïs transgénique dans la production commerciale des États-Unis et autres pays, on s'est fortement préoccupé de la culture et de la consommation des maïs transgéniques introduits au Mexique notamment dès la parution du rapport sur la contamination des populations indigènes de maïs avec des transgéniques dans l'État de Oaxaca (Quist \& Chapela 2001).

Les travaux de conservation in situ et la sélection participative du maïs ont démarré vivement avec le projet «Milpa» (1995-2001); quatre universités nord-américaines et quatre institutions mexicaines de recherche y ont participé. Ce projet a été financé par la fondation McKnight qui a opéré fondamentalement dans la région ChalcoAmecameque et dans le nord de la Sierra de Puebla (Ortega 2000, 2004) (Figure 8). Il s'en est suivi plusieurs projets de conservation in situ et de sélection participative du maïs, menés par différentes institutions nationales et internationales (Ortega 2000). 
Figure 8 : Chercheurs mexicains et nord-américains du « Projet Milpa » (1995-2001) lors d'une visite de terrain dans la partie sud-ouest de l'État de Mexico

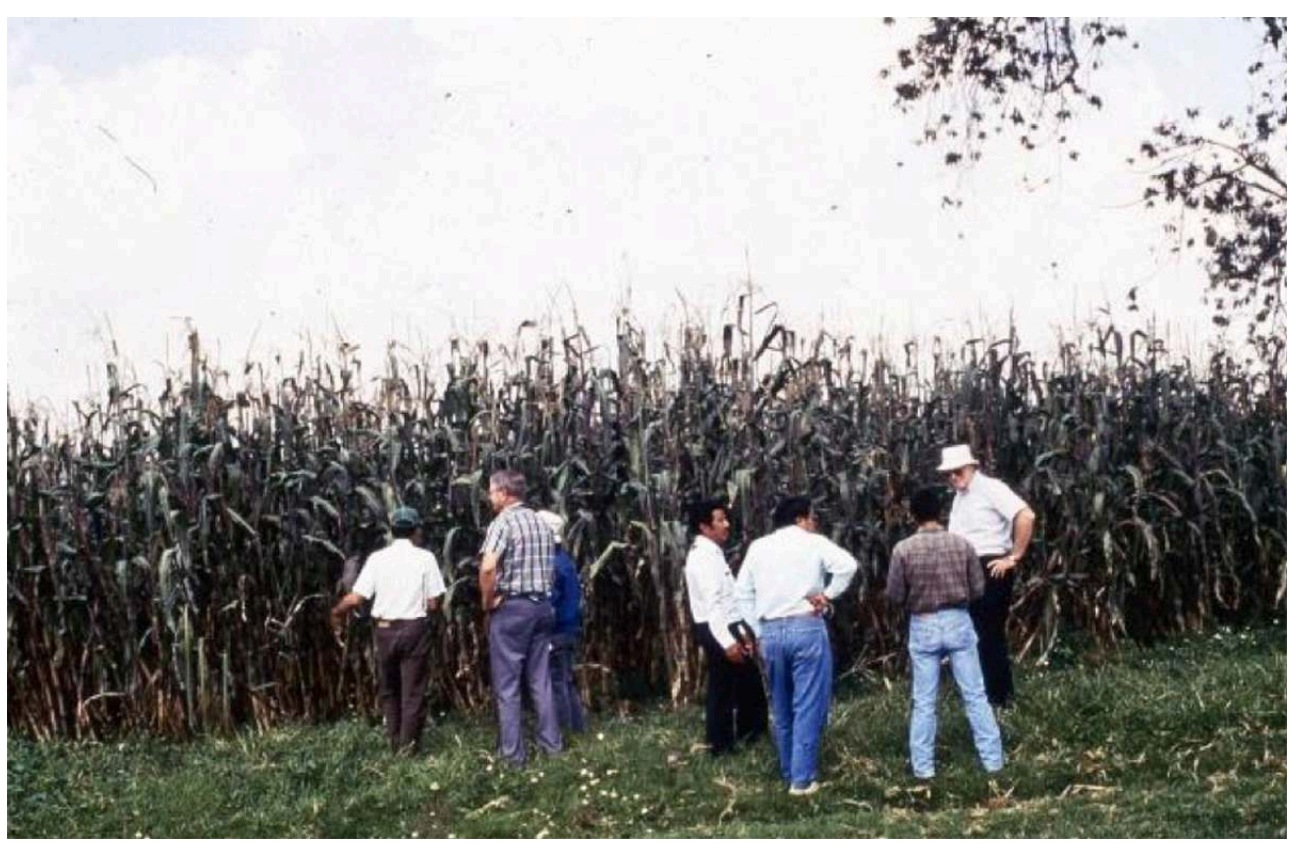

(c) R. Ortega Paczka les populations natives de maïs a été motivée par la détection de la contamination par les transgéniques à Oaxaca, et dans de nombreuses autres régions du pays. Quand on eut récolté ces maïs dans presque tout le pays et qu'on eut obtenu un diagnostic des territoires où sont semés presque exclusivement des hybrides commerciaux de maïs, le gouvernement fédéral mexicain et ses institutions ont cessé de s'intéresser aux études des maïs natifs, dès 2012. En revanche, l'État mexicain, pressé par Monsanto et les États-Unis, a autorisé et promu l'usage de paquets technologiques contenant des semences transgéniques, surtout dans les États du nord du pays, notamment dans les territoires où prédomine la plantation d'hybrides obtenus à partir de techniques conventionnelles. Cependant, l'autorisation de la culture des transgéniques n'a pas abouti, du fait de la résistance des nombreuses organisations de la société civile, des scientifiques ainsi que des groupes paysans et plus précisément avec l'Arrêt du 8 mars 2016 du Segundo Tribunal Unitario en Materias Civil y Administrativa (Second tribunal Unitaire en Matières civiles et administratives) qui ordonne à SAGARPA (Secretaría de Agricultura, Ganadería, Pesca y Alimentación) de s'abstenir d'octroyer des permis de diffusion ou de plantation de maïs transgénique jusqu'à ce que le jugement collectif des scientifiques, experts et paysans soit réglé.

De multiples critiques contre l'autorisation de la plantation et à la consommation du maïs transgénique au Mexique ont surgi ; l'une d'elles est la difficulté de restreindre la culture de ces maïs dans les territoires où ils sont autorisés et d'éviter la contamination d'autres zones par le transfert de ces semences que les travailleurs de ces champs pourraient, par curiosité, emporter à leurs régions d'origine, contaminant ainsi leurs populations indigènes en mélangeant les semences ; mais également et plus rapidement la diffusion du pollen de ces champs contenant des transgéniques emporté par le vent, et qui viendrait tomber sur les plantes de maïs natifs et les engrais (Álvarez-Buylla \& Piñeyro 2013). 
Cette propension du gouvernement mexicain à encourager la plantation de maïs transgénique a réduit, dès 2013, les financements pour l'étude des populations endémiques de maiis et la promotion de leur sélection génétique ; ils deviennent quasi inexistants. Un des rares projets mis en place par le gouvernement fédéral fut de "rémunérer les services de conservation" (pago por servicios de conservación), sous la responsabilité de la Comisión Nacional de Áreas Naturales Protegidas del Ministerio del Medio Ambiente (Commission Nationale d'Espaces Naturels protégés) mise en place par le Ministère de l'Écologie. Ce projet octroie des subventions à environ 500 paysans mexicains pour qu'ils conservent leurs populations natives de maïs (ceci sur un total estimé à deux millions de paysans qui cultivent des semences natives de maïs dans le pays). De 2010 à 2013, le programme "custodios" (gardiens) organisé par le Sistema Nacional de Recursos Fitogenéticos (Système National de Ressources Phytogénétiques), organisme dépendant de la SAGARPA (Ministère de l'agriculture, de l'élevage, de la pêche et de l'alimentation), attribuait des subventions en nature, principalement des agrochimiques, à environ 500 agriculteurs qui cultivent des populations indigènes de maïs qui représentent environ 60 races indigènes du pays.

\section{La sélection participative du maïs au Mexique et ses diverses modalités}

31 Depuis la fin des années 1940 jusqu'au début des années 90 dans les milieux officiels au Mexique, a prédominé l'idée que le futur du maïs dépendait des sélecteurs qui travaillaient sur des bases scientifiques. Même si l'importance des paysans dans l'évolution des maïs indigènes était reconnue, certaines connaissances et pratiques paysannes étaient considérées comme relevant du passé et sans importance pour le futur de la culture de la plante. Cette reconnaissance exclusive de la science occidentale pour l'amélioration de la production des aliments au Mexique s'exprime par le texte du Dr. Oscar Brauer Herrera en 1968 écrit alors qu'il occupait le poste de directeur du Colegio de Postgrados (École d'études du 4ème niveau). Il a ensuite été Ministre de l'agriculture et de l'élevage :

«... l'augmentation de la production ne pourra s'accomplir que quand toutes les connaissances scientifiques s'appliqueront à l'agriculture. L'agriculture n'est pas une science mais l'application de plusieurs sciences. Si l'on étudie et que l'on travaille et que les résultats soient appliqués au développement économique de l'agriculture, elle sera progressiste et les rendements des terres seront plus élevés. Si l'agriculture continue à être gérée en la considérant comme un art, ou n'importe quoi d'autre, et que sa production dépend de Ceres ou Xipe, la production continuera au stade où ces déesses étaient vénérées » (Brauer 1968).

Toutefois, depuis les années 1970, de gros problèmes apparaissent dans la sélection centralisée du maiis; plus précisément, dans les hybrides, qui se comportaient de manière remarquable dans les parcelles d'expérimentation où ils étaient obtenus. Celles-ci se caractérisaient par la profondeur de ses sols, l'accès à l'irrigation, et une fertilisation abondante; mais quand ces hybrides se cultivaient dans les conditions auxquelles les paysans étaient soumis, le rendement était dépassé par les populations de maïs natifs (Muñoz et al. 1976). L'inefficience la plus avérée a été observée par des programmes de sélection dans les régions à saisons différenciées. Pour combler cette déficience, dans ces régions à saisons différenciées, on est parti du recueil des populations natives de maïs d'une région, on a évalué le matériel réuni dans plusieurs 
champs de paysans, on a également utilisé, comme matériau de départ pour la sélection, les meilleures populations natives de maïs, et on les a choisies et évaluées dans les parcelles des agriculteurs et pas seulement dans les parcelles d'expérimentation. De plus, pour évaluer les conditions des petits producteurs dans les régions à saisons différenciées, on a recommandé que les programmes soient dirigés principalement vers l'obtention de variétés à pollinisation libre, celles-ci pouvant être semées plusieurs années de suite par les agriculteurs en partant d'une semence sélectionnée dans leurs propres récoltes, et non pas dirigés vers l'obtention d'hybrides dont les agriculteurs devraient acheter la semence tous les ans, faute de quoi le rendement et l'uniformité des plantes dans leurs champs diminueraient considérablement. Malheureusement la Productora Nacional de Semillas (Fournisseur national de semences), une compagnie gouvernementale, n'a quasiment pas reproduit ni distribué les semences des variétés à pollinisation libre pour les régions à saisons différenciées générées par les sélectionneurs de l'ancien Instituto Nacional de Investigaciones Agrícolas y Pecuarias (Institut national de recherches agricoles et d'élevage).

Dans les années 50, date où les maïs hybrides ont commencé à être commercialisés, un phénomène imprévu s'est produit : des milliers de paysans se sont mis à sélectionner la semence et à la semer à partir des générations avancées de ces hybrides et à les combiner avec leurs populations natives, autrement dit, ils ont incorporé les hybrides à leurs pratiques traditionnelles (Ortega 1973).

\section{Sélection participative et ses modalités}

34 La modalité de la sélection conventionnelle mise en place par les généticiens pour obtenir des hybrides n'est pas en mesure d'englober l'énorme diversité des milieux naturels et des cultures, ainsi que l'immense diversité des variétés de maïs cultivés par les agriculteurs au Mexique; d'où le besoin de la mise en place de la sélection participative du maïs entre agriculteurs et généticiens.

Il existe de nombreuses modalités de sélection génétique qui s'appliquent aussi à la sélection participative, modalités qui sont essentiellement le résultat de la combinaison des décisions fondamentales qui sont souvent prises au début des programmes. Selon Hallauer et Miranda (1981), les sélectionneurs de plantes sont confrontés à la nécessité de prendre deux décisions : 1) choisir le matériel génétique basique du programme de sélection génétique et 2) choisir la méthode de sélection génétique. Ortiz (1993) prend en compte une troisième décision fondamentale constituée par les critères de sélection. Pour notre part, nous considérons une quatrième décision fondamentale concernant une approche qui prend appui sur l'ampleur de la surface pour laquelle le programme a été conçu et s'il est participatif ou non.

En ce qui concerne le matériel génétique basique, il peut être : a) matériel autochtone local ou introduit d'autres régions, b) matériel amélioré par les sélectionneurs, c) une combinaison des deux.

Quant à la méthode de sélection il y a une infinité de variables, mais le plus important est le but qui peut être l'obtention de variétés de pollinisation libre, d'hybrides ou les deux.

Au début de l'application des critères de sélection du maïs au Mexique, la priorité n'était quasiment que le rendement du grain, mais à partir du milieu des années 
soixante du siècle dernier l'intérêt a porté sur l'amélioration du type de la plante, la résistance à la maladie et la qualité du grain.

Concernant la zone du programme de sélection, elle peut être celle des terres d'une communauté, d'une région ou la recherche d'une adaptabilité à un échelon ample d'environnements.

\section{Sélection Massale Visuelle Stratifiée (SMVE)}

Quand on se réfère à la sélection participative la méthode la plus employée, tout au moins au Mexique, est celle de la Sélection Massale Visuelle Stratifiée (SMVE) (Molina 1981), bien que d'autres méthodes comme la sélection de demi-frères, des frères complets, ou tout simplement la sélection visuelle de la plante et de l'épi dans le champ peuvent être appliquées.

Un des aspects innovateurs de la SMVE par rapport à la sélection traditionnelle des semences utilisée par les agriculteurs mexicains consiste dans la sélection des plantes qui vont contribuer avec des semences pour les futures générations. C'est-à-dire non seulement les épis qui présentent de bonnes caractéristiques à l'issue de la récolte mais la sélection des plantes et des épis qui manifestent les caractères adéquats sur le terrain.

Plusieurs sélectionneurs ont commencé à promouvoir la Sélection massale moderne ou Sélection Massale Visuelle Stratifiée (SMVE) (Molina 1981, Aveldaño et al. 1977) en collaboration avec des paysans pour améliorer les caractéristiques de la plante, de l'épi et le rendement (Figure 9). Ces efforts ont été, généralement, déployés sans le soutien des pouvoirs publics et leur accomplissement s'est heurté à des difficultés telles que :1) l'habitude des agriculteurs des Hauts plateaux centraux du Mexique de couper les plantes dont les épis sont mûrs mais encore trop humides et de les empiler verticalement (comme on voit dans la figure 10) pendant un ou deux mois, bien avant que les épis se décrochent de la plante, c'est-à-dire la véritable récolte ;2) la sélection la plus minutieuse se réalise pendant la récolte, alors que les agriculteurs sont submergés par le travail ;3) un autre problème surgit lorsque la SMVE a été appliquée pendant plusieurs années dans la même parcelle, et que le matériel est transplanté dans un autre terrain. Les bénéfices de la sélection diminuent alors surtout en rendement. Généralement la durée de ces projets n'a pas été garantie, à l'exception des travaux conduits par le Dr. Fernando Castillo du Colegio de Postgraduados dans le sud-est de l'État de Mexico et la Sierra nord de Puebla (Zambrano 2013). 
Figure 9 : Le maïs natif présente souvent des carences telles que sa très grande taille et les plantes ont tendance à tomber, ce qui peut être résolu en appliquant une selección visual en planta ou selección masal visual estratificada

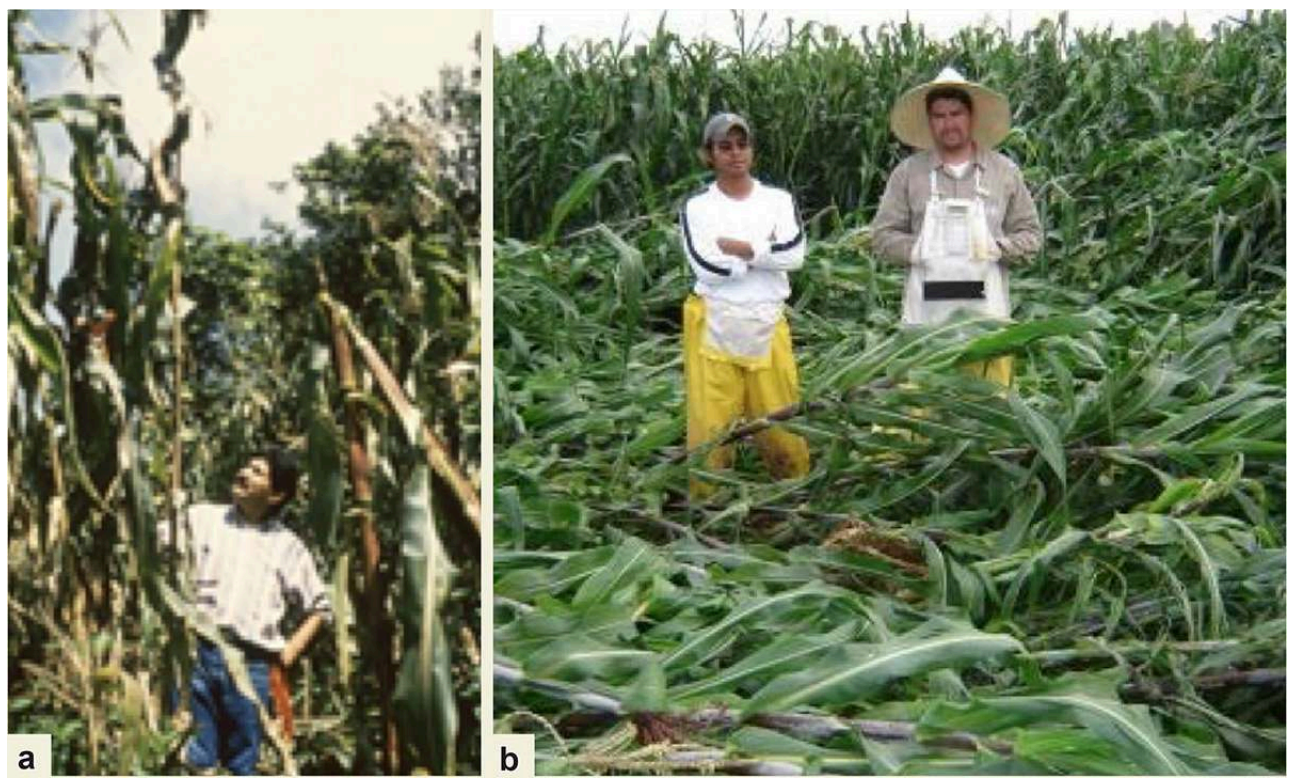

(c) R. Ortega Paczka

Figure 10 : Des difficultés ont été constatées dans la selection massale pour des causes telles que la pratique des agriculteurs dans les hautes vallées centrales du Mexique consistant à couper les plants avec les rafles mûres mais encore très humides et à les égoutter

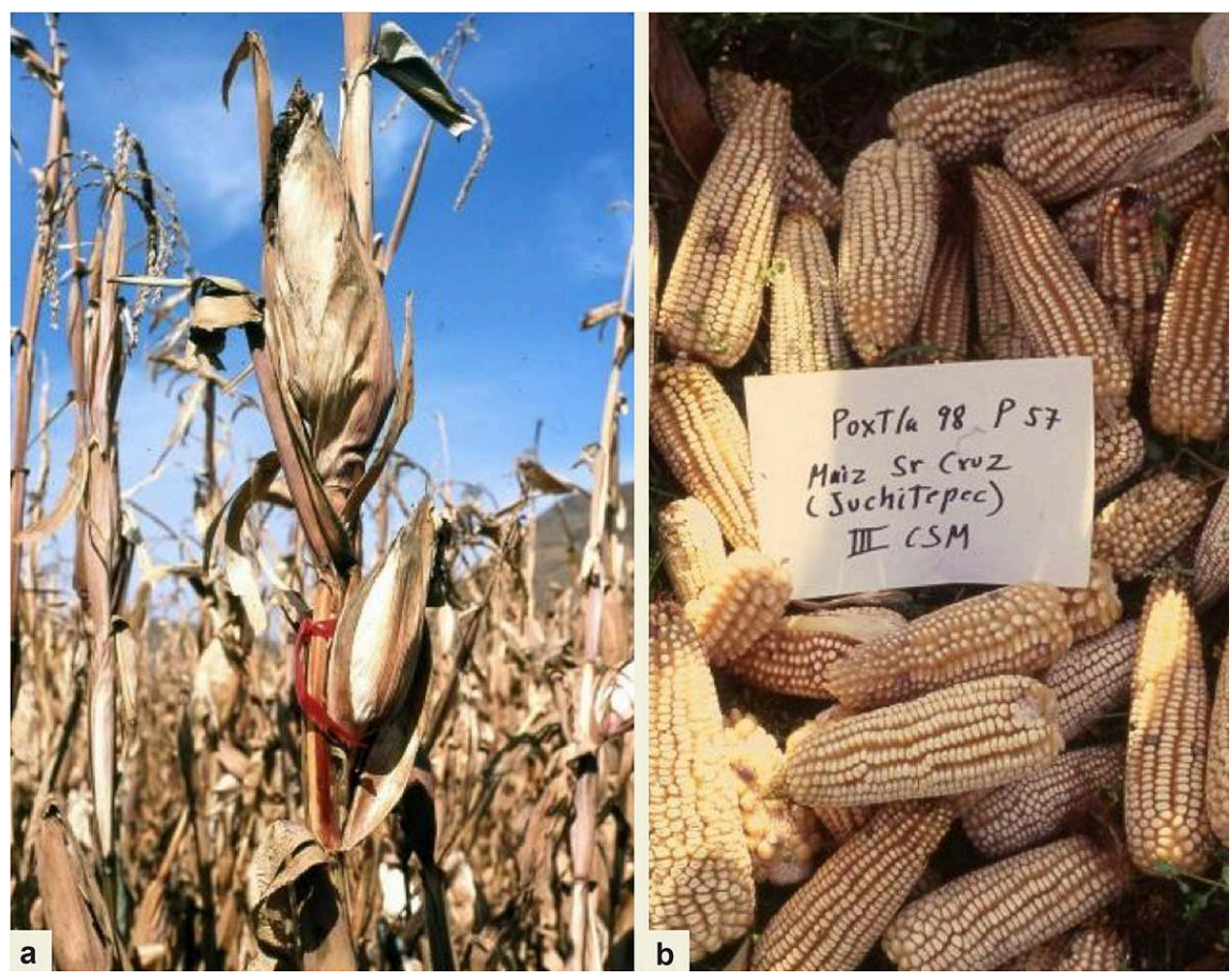




\section{Pour la Sélection Massale Visuelle Stratifié (SMVE)}

Une superficie d'environ un demi-hectare $\left(5000 \mathrm{~m}^{2}\right)$ doit être délimitée dans le champ de maïs et où la milpa est de préférence assez uniforme.

Il faut déterminer quels caractères l'agriculteur souhaite sélectionner et ceux choisis par le sélectionneur, comme : l'élimination des épis ou des plantes d'autres types qui sont généralement le résultat de croisements avec d'autres sortes de maïs ; sélectionner la qualité des épis, par exemple : la couleur choisie la plus intense (bleu, jaune ou autre) ; l'élimination de la pourriture dans l'épi ; diminuer la taille moyenne des plantes et tenter qu'elles aient une tige et une racine fortes pour qu'elles ne soient pas arrachées par des vents forts; éliminer les plantes qui ne produisent pas d'épis ou celles qui ont des bourgeons stériles; augmenter le rendement du grain; également que les feuilles des épis soient de bonne qualité pour être vendues comme enveloppes de tamales; que la paille sèche ne soit pas rigide et désagréable pour le fourrage. Certains caractères peuvent ne pas présenter de valeur marchande mais ils peuvent plaire aux agriculteurs, comme les rangs des grains droits dans les épis ou les feuilles violettes.

Dans la SMVE, et cela peut être appliqué à d'autres méthodes de sélection, trois stades de sélection sont suggérés.

La première phase consiste à faire la sélection peu avant la pollinisation et à enlever les épis des plantes malades, celles qui semblent ne pas produire d'épis, celles dont les efflorescences mâles et femelles ne coïncident pas ou celles qui présentent des caractères indésirables (trop hautes, trop tardives, trop penchées ou qui poussent des bourgeons infertiles). Cette première phase requiert que la personne qui sélectionne sillonne le champ plusieurs fois car la floraison des populations natives se produit généralement pendant plus d'une semaine et il est nécessaire de procéder progressivement à l'arrachage des plantes, pour qu'elles puissent être pollinisées et que les possibles faiblesses des caractères puissent être repérées.

Pour la deuxième phase de la sélection, on recommande que la plupart des plantes soient mûres physiologiquement (quand une couche noire se forme à la base du grain). Celles qui présentent les caractères favorables recherchés sont alors marquées par une bande en polyéthylène, ou en tissu ou avec de la peinture. Il est préconisé de marquer entre 500 et 600 plantes dans le demi-hectare.

La troisième phase de sélection se réalise peu avant la récolte. À cette étape, la totalité de la parcelle doit être divisée en petits lots uniformes de 60 à $100 \mathrm{~m}^{2}$. La forme des lots dépendra de la possible direction de l'hétérogénéité du terrain. Si le terrain ne présente pas une pente qui diminue la fertilité, les lots doivent être carrés (entre 8 et 12 sillons, chacun long de 12 mètres). En revanche, si le terrain est en pente forte, les lots choisis doivent être rectangulaires et les côtés correspondant à la largeur doivent occuper le sens de la pente. Dans cette troisième phase, on ne récolte que les épis des plantes marquées favorablement dans l'étape précédente et qui sont en concurrence directe, c'est-à-dire, qu'elles sont voisines d'autres plantes par tous les côtés. Ensuite, les épis des plantes marquées et récoltées sont disposés au milieu des lots et les épis qui ne possèdent pas les caractères souhaités sont rejetés. Le même nombre de plantes doit être sélectionné dans les bons lots et dans les mauvais, afin de que les épis sélectionnés proviennent de secteurs où la terre possède des caractères variés et ne pas avantager celles qui sont issues des terres de meilleures conditions. Des 500 ou 600 plantes 
marquées dans l'étape précédente seule la moitié sera sélectionnée en raison des bons caractères des épis.

Pour obtenir un composé équilibré, on recommande, qu'au moment de l'égrainage des épis sélectionnés, chacun d'entre eux contribue à la composition qui sera utilisée comme semence avec plus ou moins le même nombre de graines.

Mon expérience personnelle avec la SMVE m'a amené à la réduire à la seconde et troisième phase qui ont été détaillées. J'ai trouvé la première peu efficace et laborieuse, c'est-à-dire celle d'enlever les épis des plantes qui présentent des caractères indésirables; car la plupart des faiblesses apparaissent après la floraison et pour obtenir de bons résultats il faut arracher les épis de beaucoup de plantes $(25 \%$ au maximum pour ne pas ralentir la pollinisation); à noter aussi que si cette opération n'est pas faite avec le plus grand soin, il y a risque d'endommager les feuilles du haut de la plante, ce qui empêche le développement des épis car ces feuilles supérieures apportent le plus de nutriments aux épis en développement.

\section{Sélection Visuelle de la plante et de l'épi}

51 La SMVE a été promue dans différentes parties du pays pendant plus de trente ans, même si cela a été fait de façon discontinue. Pourtant les agriculteurs ne l'ont pas adoptée. Ceci est dû, entre autres, aux raisons suivantes :

52 a) les résultats sont modestes pendant un premier cycle (Zambrano (2013), rapporte pour dix maïs dans le sud-est de l'État de Mexico : 2,4\% de rendement, 0,5\% de diminution de la hauteur de la plante et 7,3\% de diminution de la pourriture de l'épi), même si les résultats cumulés pendant plusieurs années de sélection sont très significatifs ;

53 b) les programmes de stimulation à l'utilisation de cette pratique n'ont duré que peu d'années et n'ont pas eu ni les ressources humaines ni l'infrastructure suffisantes ;

54 c) fréquemment, après la culture du même maïs pendant plusieurs années, l'agriculteur doit le changer pour répondre aux demandes du marché ou parce qu'il trouve une variété meilleure, autrement dit, il préfère obtenir une variété supérieure qu'améliorer la sienne ;

55 d) comme il a été énoncé auparavant, la partie la plus importante de la Sélection Massale se réalise pendant la période de récolte quand l'agriculteur est submergé par le travail ;

e) la SMVE requiert une équipe d'au moins trois personnes et que généralement l'agriculteur n'a pas assez de personnel.

57 De par ces situations, nous ne promouvons pas la SMVE au Mexique mais la simple « sélection visuelle de la plante et de l'épi ». Celle-ci n'exige pas la création de lots avec plusieurs sillons et elle peut être faite par une seule personne. Mais pour que cette pratique soit avantageuse, l'agriculteur doit respecter les autres consignes de la SMVE, c'est-à-dire : a) être faite dans environ un demi-hectare au milieu de la parcelle; b) parcourir tous les sillons ou bien un sur deux, sélectionner et ne marquer que les plantes ayant des caractères remarquables et qui sont en concurrence directe, c'est-ádire, qui sont voisines par tous les côtés d'autres plantes ayant des caractères remarquables; c) opérer une pression sélective de $10 \%$ ou plus des plants, puis faire une sélection d'épis de $50 \%$ ou plus; autrement dit, en sélectionnant la meilleure 
plante parmi les dix, on conserve les épis qui présentent les caractères souhaités, dans le cas contraire on s'en débarrasse. Avec cette méthode, la pression sélective sera réduite de $5 \%$ ou plus, cette proportion qui a prouvé son efficacité dans la SMVE.

\section{Modalités de sélection mises en place dans le sud-est de l'État de Mexico, Mexique} région voisine de la zone métropolitaine de la ville de Mexico, utilisent la méthode dite de « retrocruza limitada (entrecroisement limité)» (Márquez et al. 2000) avec certaines variantes pour l'adapter à la sélection participative (Ortega \& Moreno 2014). La méthode qui résulte se compose des phases suivantes :

59 a) Récolter des semences issues de populations indigènes de maïs des agriculteurs, en introduisant des semences issues de populations natives de maïs ayant des caractères remarquables et provenant d'autres régions similaires du pays.

b) Évaluer ces populations natives de maïs par des expériences dans les terres des agriculteurs et dans la station expérimentale de l'Université. La désignation des meilleurs matériaux est faite par le paysan et le sélectionneur.

61 c) Croiser les populations natives de maïs ayant des caractères remarquables issus de ces expériences avec les matériaux sélectionnés dans la station expérimentale de l'Universidad Autónoma de Chapingo.

d) Reprendre les croisements obtenus deux ou plusieurs années auparavant et procéder à une sélection légère pour rassembler les caractères des deux progénitures. prometteuses de grain blanc et violet ont été obtenues.

\section{Types et niveaux de participation des agriculteurs dans la sélection participative}

e) Évaluer les populations obtenues dans les champs des agriculteurs.

f) Entrecroiser le matériel résultant avec la population indigène, en obtenant une population avec $75 \%$ de gènes créoles.

g) Cultiver la population obtenue de l'entrecroisement pendant plusieurs années, de préférence dans les terres des paysans, travaillées par les paysans et continuer la sélection jusqu'à obtention des caractères souhaités.

Grâce à ces sélections successives, qui ont duré quasiment 15 ans, des variétés

Morris \& Bellon (2004) rapportent sept types de participation des agriculteurs à la sélection participative (Mode of participation in participatory plant breeding (PPB)) :

- Les agriculteurs reçoivent les variétés finalisées développées par les sélectionneurs.

- Les agriculteurs fournissent la source génétique dans le processus de sélection.

- Les agriculteurs identifient les traits qui doivent être améliorés et suggèrent des critères de sélection.

- Les agriculteurs évaluent les variétés acquises dans la station ou dans des parcelles expérimentales.

- Les agriculteurs testent les matériaux inachevés (lignées, familles, variétés locales) dans la station ou dans les parcelles gérées par les obtenteurs et sélectionnent les matériaux pour des améliorations postérieures.

Revue d'ethnoécologie, Supplément 2 | 2021 
- Les agriculteurs conduisent des essais d'évaluation du matériel génétique dans leurs propres champs avec leur propre gestion.

- Les agriculteurs reçoivent des formations sur les méthodes « scientifiques » de sélection.

\section{Les principales difficultés qui s'opposent aux projets de conservation in situ et à la sélection participative des maïs du Mexique.} sélection participative.

b) La plupart du personnel qui travaille dans ces projets a été formé et travaille dans des projets de conservation ex situ et des projets de sélection génétique conventionnels. c) Généralement les responsables de ces projets ne consacrent qu'une petite partie de leur temps au travail direct avec les agriculteurs dans ces projets ; ils sont pris par leurs activités quotidiennes dans les institutions comme : dispenser des cours, s'occuper des étudiants pour des thèmes éloignés du sujet de cet exposé, donner des conférences, contrôler des travaux d'édition, réaliser des activités administratives et enfin réunir la documentation pour participer à des concours et ainsi obtenir des promotions.

d) La difficulté du travail interdisciplinaire et en équipe en raison de la formation spécialisée du personnel ainsi que les conflits d'intérêt entre les institutions participant à ces projets.

71 À partir de ce que nous venons d'exposer concernant le personnel technique des projets, les faiblesses peuvent être résolues surtout par une meilleure préparation, par le conseil averti et par la professionnalisation dans le sujet.

\section{Problèmes éprouvés par les communautés rurales qui participent á ces projets}

72 a) La capacité et le peu d'intérêt des agriculteurs pour améliorer leur production de maiis principalement en raison du bas coût du grain issu de l'ouverture du marché du pays et le faible soutien du gouvernement à la production. Le manque d'intérêt s'explique aussi car les avancées qui s'obtiennent dans chaque cycle sont minces et généralement les agriculteurs préfèrent accepter les paquets technologiques subventionnés qui contiennent des semences hybrides et qui assurent une hausse considérable et immédiate de rendement.

b) Les paysans changent fréquemment la population des maïs qu'ils cultivent en raison des gelées, des sécheresses ou en réponse aux demandes du marché quand le coût d'un 
autre maïs est plus haut.

c) Récemment, on a observé qu'un nombre important de paysans négligent leurs parcelles ou qu'ils arrêtent, tout simplement, de les cultiver. Dans certains cas, du fait d'une émigration temporaire, les paysans ne sont pas dans la communauté quand il faut faire les travaux de sélection participative.

d) Une autre cause du peu d'intérêt pour quelques variétés locales de maïs pour l'autoconsommation est que ces maïs sont remplacés par des marchandises disponibles dans les épiceries. Celles-ci s'achètent avec l'argent envoyé par les migrants ou celui des aides gouvernementales pour la lutte contre la pauvreté.

e) Le manque d'organisation des petits producteurs de maïs, ce qui complique le conseil et l'adoption massive des innovations qui amélioreraient la production, comme celles relatives à la conservation et á la sélection participative de leurs populations natives. Ceci s'explique principalement par le fait que les petits producteurs de maïs emploient la plus grande partie de leur production pour l'autoconsommation en famille, ils n'ont donc aucun intérêt à s'organiser et ils agissent de façon isolée. Les quelques organisations de petits agriculteurs de maïs qui existent ne s'occupent pas des aspects productifs, au contraire de l'exemple des petits producteurs de café ou de miel pour qui l'organisation a été nécessaire principalement pour commercialiser leurs produits.

f) Les conséquences négatives d'autres projets et programmes où les techniciens prennent le contrôle des parcelles encourageant la passivité de la part des agriculteurs. g) Le manque d'information des agriculteurs et des paysans sur les impacts négatifs des paquets technologiques promus par le gouvernement et les compagnies agrochimiques. Les problèmes concernant les communautés rurales sont, dans l'ensemble, plus compliqués à résoudre car il faudrait un changement radical des politiques publiques, la valorisation de la culture traditionnelle agricole, la prise de conscience des populations rurales et urbaines de la supériorité des aliments traditionnels par rapport aux industriels, le développement de marchés pour la diversité du maïs, la promotion des meilleurs prix pour le grain et les différents types de maïs.

\section{Réflexions pour conclure}

$73 \mathrm{Au}$ Mexique, on conserve une grande diversité de maïs indigènes car le pays est son centre d'origine. Ces maïs occupent environ $28 \%$ du territoire agricole (5 $000000 \mathrm{ha}$ ) et cette superficie comprend une immense diversité d'environnements naturels et de conditions agricoles. Divers usages perdurent et souvent à un usage particulier correspond un ou plusieurs types de maïs.

La conservation in situ de la diversité des maïs est opérée par environ deux millions de familles paysannes, dont $80 \%$ cultivent les maïs indigènes, et sélectionnent leurs semences à partir de leur récolte. Cet acquis des connaissances et des savoirs doit être bien valorisé et soutenu par les politiques publiques.

Pendant les derniers 70 ans (1944-2016), il y a eu des périodes de grand intérêt public pour les études, les collectes, et la conservation de la diversité des maïs indigènes au Mexique, et dernièrement entre 2001 et 2012. Mais actuellement le gouvernement s'est désengagé du sujet en prenant parti pour la culture des maïs transgéniques, ce qui a affaibli la résistance des chercheurs, des ONG et des groupes d'agriculteurs, notamment en raison d'une procédure judiciaire en cours. 

pendant des millénaires, de la conservation in situ et sélection participative des maïs natifs par des projets, relativement contemporains. Cette dernière modalité doit aussi être promue par des politiques publiques.

a la sélection génétique participative entre agriculteurs et sélectionneurs, il y a un éventail considérable de modalités qui mettent en avant d'un côté le type et le niveau de participation des agriculteurs, et de l'autre, le matériel de départ, les méthodes de sélection, les critères de sélection et la perspective.

meincipale méthode de sélection des maïs natifs recommandée depuis 40 ans est la Sélection Massale Visuelle Stratifiée (SMVE); cependant, celle-ci n'a pas été adoptée par les agriculteurs. Nous proposons une méthode plus simple de sélection qui tient compte des vertus de la SMVE.

Pour obtenir les meilleurs résultats, les projets d'observation in situ et la sélection participative des maïs natifs doivent être accompagnés par des pratiques d'amélioration des terres, par la conservation de l'humidité des sols, par l'amélioration de la gestion des cultures et par le développement des marchés pour une telle diversité des maïs.

Plusieurs difficultés ont été observées dans la réalisation des projets de conservation in situ et de la sélection participative des maïs indigènes tant de la part des communautés paysannes que de celle des techniciens et chercheurs qui y participent. Dans le cas du personnel technique et scientifique des projets, les faiblesses détectées peuvent être résolues d'abord par une meilleure préparation, par le conseil averti et par la professionnalisation dans le sujet. Les problèmes rencontrés par les communautés rurales sont, dans l'ensemble, plus compliqués à résoudre; certains sont causés par les paysans qui cultivent principalement pour leur autoconsommation. D'autres requièrent un changement radical des politiques publiques, ainsi que la prise de conscience des avantages des pratiques agricoles et de consommation traditionnelles du maïs par rapport aux usages et consommation des marchandises industrielles.

À Jorge Quetzal Argueta Prado, Marianna Fenzi et María Gabriela Zurita-Benavides, ainsi qu'à l'Ingénieur en Agroécologie Baruch X. Chamorro Cobaxin qui a fait les corrections des versions antérieures et a proposé des suggestions importantes. De même, Renán Pérez González qui a édité les photographies de l'article.

\section{BIBLIOGRAPHIE}

Álvarez-Buylla E. \& Piñeyro A. (Ed.) 2013 - El maíz en peligro ante los transgénicos: Un análisis integral sobre el caso de México. UNAM (Universidad Nacional Autónoma de México)-Centro de Investigaciones Interdisciplinarias en Ciencias y Humanidades, Unión de Científicos Comprometidos con la Sociedad, $568 \mathrm{p}$.

Anderson E. \& Cutler H. C. 1942 - Races of Zea mays: I. Their recognition and classification. Ann. Mo. Bot. Gard. 29 : 69-86.

Revue d'ethnoécologie, Supplément 2 | 2021 
Aquino P, Carrion F, Calvo R \& Flores D. 2001 - Selected Maize Statistics. In : Pingali P.L. (Ed.) 2000 World Maize Facts and Trends, Meeting World Maize Needs: Technological Opportunities and Priorities for the Public Sector. CIMMyT : 45-60.

Aveldaño Salazar R., Carballo Carballo A. \& González Hernández V. 1977 - Fórmulas de producción y mejoramiento del maíz en el estado de Tlaxcala. Chapingo, Estado de México, Centro de Investigaciones Agrícolas de la Mesa Central, Instituto Nacional de Investigaciones Agrícolas (ahora INIFAP-SAGARPA), 28 p. (Circular CIAMEC ; 95).

Beas C. 1982 - Los libros del maíz: Cómo lo usamos. México, Árbol Editorial S.A. de C. V. e Instituto Nacional para la Educación de Adultos, 101 p.

Brauer Herrera O. 1968 - La tecnología y la ciencia en el desarrollo de la agricultura. In : Diagnóstico de las ciencias agrícolas en México. México, Centro Nacional de la Productividad : 4-5.

CONABIO 2011 - Base de datos del proyecto global "Recopilación, generación, actualización y análisis de información acerca de la diversidad genética de maíces y sus parientes silvestres en México". Octubre de 2010. México, D. F., Comisión Nacional para el Conocimiento y Uso de la Biodiversidad. [En ligne :] http://www.biodiversidad.gob.mx/genes/proyectoMaices.html. Consultado 9/10/2015

Hallauer A.R. \& Miranda J.B. 1981 - Quantitative Genetics in Maize Breeding. Ames, Iowa State University Press, 469 p.

INEGI 2015 - Estadísticas históricas de México 2014. [En ligne :] http://www.inegi.org.mx/ prod_serv/contenidos/espanol/bvinegi/productos/nueva_estruc/HyM2014/9.\%20Agropecuario, \%20aprovechamiento.pdf (Consultado 02-02-2016).

Kato Yamakake T.A. 2009 - Teorías sobre el origen del maíz. In : Kato Yamakake T.A., Mapes Sánchez C., Mera Ovando L.M., Serratos Hernández J.A. \& Bye Boettler R.A. (Ed.) Origen y diversificación del maíz: una revisión analítica. México, Universidad Nacional Autónoma de México y Comisión Nacional para el Conocimiento y Uso de la Biodiversidad : 43-68.

Lépiz Ildefonso R. \& Rodríguez Guzmán E. 2006 - Los recursos fitogenéticos de México. In : Molina Moreno J. \& Córdoba Téllez L. (Ed.) Recursos fitogenéticos de México para la alimentación y la agricultura. Chapingo. México, SAGARPA y Sociedad Mexicana de Fitognética : 1-17.

Márquez Sánchez F., Sahagún Castellanos L., Carrera Valtierra J. \& Barrera Gutiérrez E. 2000 Retrocruza limitada para el mejoramiento genético de maíces criollos. Chapingo Estado de México, Universidad Autónoma Chapingo, 53 p.

Matsuoka Y., Vigouroux Y., Goodman M.M., Sánchez González J., Buckler E.S. \& Doebley J.F. 2002 - A single domestication for maize shown by multilocus microsatellite genotyping. Proceedings of the Natural Academy of Sciences of the USA $99: 6080-6084$.

Molina Galán J.D. 1981 - Selección Masal Visual Estratificada en Maíz. Chapingo, Estado de México, Colegio de Postgraduados, 35 p.

Morris M.L. \& Bellon M.R. 2004 - Participatory plant breeding research: Opportunities and challenges for international crop improvement systems. Euphytica $136: 21-35$.

Muñoz Orozco A., Carballo Carballo A. \& González Hernández V. 1976 - Mejoramiento del maíz en el CIAMEC. Análisis crítico y reenfoque del programa. Memoria del VI Congreso Nacional de Fitogenética. Montyerrey, Nuevo león, México, Sociedad Mexicana de Fitogenética : 124-130.

Ortega Paczka R. 1973 - Variación en maíz y cambios socieconómicos en Chiapas, México, 1946-1971. Tesis de Maestría. Rama de Botánica, Colegio de Postgraduados. Chapingo, México, 200 p. 
Ortega Paczka R. 1977 - Reorganización del mejoramiento genético del maíz en el INIA. In : Hernández Xolocotzi E. (Ed.) Agroecosistemas de México. México, Colegio de Postgraduados : 369-390.

Ortega Paczka R. 2000 - Los proyectos de conservación in situ y mejoramiento participativo en México. Revista de Geografía Agrícola 31 : 97-108.

Ortega Paczka R. 2003a - La diversidad del maíz en México. In : Esteva G. \& Marielle C. (Ed.) Sin maíz no hay país. México, Museo Nacional de Culturas Populares :123-154.

Ortega Paczka R. 2003b - Principales logros y problemas de los proyectos de conservación in situ y mejoramiento participativo de maíz en México. Delpinoa 45 : 109-116.

Ortega Paczka R. 2004 - Experiencias del proyecto Milpa en maíz (Zea mays L.) en ChalcoAmecameca, México en su primera etapa. In : Chávez Servia J.L., Tuxill J. \& Jarvis D.I. (Ed.) Manejo de la diversidad de los cultivos en los agroecosistemas tradicionales. Cali, Colombia, Instituto Internacional de Recursos Fitogenéticos : 90-96.

Ortega Paczka R. 2010 - Hacia la conservación y mejoramiento in situ de la diversidad del maíz de México. In : Agricultura, Ciencia y Sociedad Rural: 1810-2010. Volumen I: Recursos Naturales y Sociedad Sustentable. Chapingo, Universidad Autónoma Chapingo : 223-253.

Ortega Paczka R. \& Ángeles Arrieta H.H. 1978 - Maíz. In Cervantes Santana T. (Ed.). Recursos genéticos disponibles a México. México, Sociedad Mexicana de Fitogenética. Pp. 75-84.

Ortega Paczka R. \& Moreno Moreno M. 2014 - Mejoramiento de maíz para el sureste del Estado de México y dos variedades obtenidas en el proyecto. Chapingo, Estado de México, Universidad Autónoma Chapingo : 80-88. (Memorias de la XXX Presentación de Trabajos de Investigación, Producción y Servicio de la Universidad Autónoma Chapingo).

Ortiz Cereceres J. 1993 - El fitomejoramiento como disciplina científica. Ciencia (Número Especial) : 85-94.

Quist D. \& Chapela I. 2001 - Transgenic DNA introgressed into traditional maize landraces in Oaxaca, Mexico. Nature 414 : 541-543.

Sanchez G.J.M., Goodman M. \& Stuber C.W. 2000 - Isozimatic and morphological diversity in the races of maize of Mexico. Economic Botany 54 (1) : 43-59.

Vavilov N.I. 1994 (1931) - México y Centroamérica como centro básico de origen de las plantas cultivadas del Nuevo Mundo. Publicado por primera vez en: Boletín de Botánica Aplicada, Genética y Fitomejoramiento (en ruso). Revista de Geografía Agrícola 20 : 15-34.

Wellhausen E.J., Roberts L.M. \& Hernández E. en colaboración con Mangelsdorf P.C. 1951 - Razas de maíz en México: su origen, características y distribución. México, D.F., Oficina de Estudios Especiales, Secretaría de Agricultura y Ganadería, 237 p. (Folleto Técnico ; 5).

Zambrano Zambrano E. 2013 - Valoración del mejoramiento genético participativo in situ en poblaciones de maíz (Zea mays L.) criollo en el sureste del Estado de México. Tesis de Maestro en Ciencias. Colegio de Postgraduados. Postgrado en Recursos Genéticos y Productividad. Montecillo, Estado de México, 61 p.

\section{RÉSUMÉS}

L'article se compose de trois parties. La première rapporte les particularités de la culture et en général les savoirs culturels qui se développent autour de la culture du maïs au Mexique, ce qui 
explique la nécessité de la préservation in situ et l'amélioration participative de l'espèce dans le pays. La seconde partie évoque très sommairement les recherches qui ont été faites sur la diversité du maïs ainsi que les tendances et problématiques liées à l'amélioration génétique de la plante. Dans la troisième partie, on expose différents aspects de la sélection participative du maïs au Mexique, en comparant particulièrement deux méthodes de sélection.

The article consists of three parts. In the first one, we address the peculiarities of maize crop more generally of the culture around maize in Mexico, in order to explain the need for in situ conservation and participatory improvement of this species. The second part mentions in very general terms, what has been done in research on the diversity of maize and the main trends and issues regarding the genetic improvement of the plant. In the third section, we expose and compare different aspects of participatory maize improvement in Mexico.

El artículo consta de tres partes. En la primera, se exponen las peculiaridades del cultivo y en general de la cultura en torno al maíz en México, lo que explica la necesidad de la conservación in situ y el mejoramiento participativo de esa especie cultivada en el país. En la segunda, se menciona en términos muy generales lo que se ha realizado en investigaciones de la diversidad de maíz y las principales tendencias y problemas en mejoramiento genético de esa planta. En la tercera parte, se exponen diferentes aspectos del mejoramiento participativo de maíz en México y se comparan en especial dos métodos de dicho mejoramiento.

\section{INDEX}

Mots-clés : maïs natifs, amélioration participative, histoire de l'amélioration végétale, culture sélective, Sélection Massale Visuelle Stratifiée (SMVE)

Index géographique : Mexique

Palabras claves : maíces nativos, mejoramiento participativo, historia del fitomejoramiento, México, Selección Masal Visual Estatificada (SMVE)

Keywords : plant genetic resources, maize land-race, participatory plant breeding, history of plant breeding, Mexico, mass selection

\section{AUTEUR}

\section{RAFAEL ORTEGA PACZKA}

Professeur-chercheur, Universidad Autónoma Chapingo 